Revista de

Contabilidade e

Organizações

www.rco.usp.br
DOI: http://dx.doi.org/10.11606/rco.v9i25.88099
Journal of

Accounting and

Organizations

www.rco.usp.br

\title{
Eficiência global no desempenho econômico-financeiro de cooperativas de crédito brasileiras
}

\author{
Vanderlei Gollo ${ }^{\mathrm{a}}$; Tarcísio Pedro da Silva ${ }^{\mathrm{b}}$ \\ ${ }^{a}$ Universidade Comunitária da Região de Chapecó \\ ${ }^{b}$ Universidade Regional de Blumenau
}

\section{Informações do Artigo}

Histórico do Artigo

Recebido: 26 de novembro de 2014

Aceito: 19 de dezembro de 2015

Palavras-chave:

Cooperativas de crédito.

Sistema de Crédito Nacional.

Desempenho econômico-financeiro.

\begin{abstract}
Resumo
O objetivo desta pesquisa consiste em verificar a eficiência global no desempenho econômico-financeiro de cooperativas de crédito brasileiras. Para tanto, adotouse a metodologia denominada pelo acrônimo PEARLS, aplicada as 25 maiores cooperativas de crédito brasileiras, para o período de 2008 a 2012. Os indicadores do PEARLS foram submetidos à Análise de Componentes Principais para seleção dos mais relevantes em termos de informação, os quais foram utilizados para determinar a eficiência das cooperativas por meio do método multicritério TOPSIS. Os resultados apontaram uma concentração de cooperativas pertencentes ao Sicoob e à Unicred entre as mais eficientes da amostra, e entre as menos eficientes há maior predominância de cooperativas filiadas ao Sicredi. As cooperativas de crédito brasileiras podem elevar seu desempenho e adequar sua estrutura com melhorias no desempenho e na eficiência, e, consequentemente, com sua principal função, que consiste em zelar pela maximização dos produtos e serviços ofertados aos cooperados.
\end{abstract}

Copyright $\mathbb{C} 2015$ FEA-RP/USP. Todos os direitos reservados

\section{INTRODUÇÃO}

A análise do desempenho das organizações, por meio das informações contidas em suas demonstrações financeiras permite fazer comparações às demais organizações e detectar as ineficiências a fim de corrigi-las e melhorar o desempenho (WESTON; BRIGHAM, 2000). Por meio dos índices é possível representar as relações entre as contas das demonstrações financeiras, fornecendo informações de forma direta sobre o desempenho das organizações (SILVA, 2001).

A análise dos indicadores econômico-financeiros destaca-se por considerar informações de diversos demonstrativos contábeis, possibilitando identificar a evolução do desempenho econômico financeiro da organização, além de projetar resultados futuros (CAMARGOS; BARBOSA, 2005). A medição do desempenho compara os níveis de realização dos objetivos, mede a eficiência na alocação de recursos e os resultados dos objetivos corporativos (YANG, 2012). O monitoramento dos indicadores permite ação direcionada a determinados índices, que dependendo dos objetivos corporativos, contribuem como uma eficaz ferramenta para maximizar o desempenho das organizações (TIAN; KETSARAPORN, 2013).

Conforme observado em Croteau (1950) e Mckee (1966) a avaliação do desempenho é fundamental também às sociedades cooperativas, visto que possibilita comparações com as demais instituições do segmento, bem como avaliar a proporção em que estão sendo atingidos os seus objetivos. Para Rosemberg (1950), a forma de atuação e o desempenho eficiente das cooperativas de crédito reduzem os custos da organização e diminui o risco dos empréstimos devido ao vínculo de interesse entre os cooperados.

Com o princípio de oferecer o melhor aos seus cooperados, as cooperativas necessitam ser eficientes em sua gestão (TRINDADE; FERREIRA FILHO; BIALOSKORSKI NETO, 2008; ALMADA et al.,2011). Na concepção de Varian (1992) a eficiência consiste na utilização máxima dos recursos com vistas a satisfazer às

Autor Correspondente: Tel (49) 3321-8000

E-mail: vande gollo@hotmail.com (V. Gollo); tarcisio@furb.br (T. P. Silva)

Unochapecó: Chapecó - R. Eduardo Pedroso da Silva, 998 - Efapi, Chapecó - SC 
necessidades dos envolvidos. É a otimização dos recursos para obtenção dos resultados planejados (FERREIRA, 2005).

No âmbito das cooperativas de crédito, para Ferreira, Gonçalves e Braga (2007, p. 428) "a eficiência está associada à capacidade de maximização dos benefícios aos cooperados, materializados em operações de créditos e benefícios líquidos, em contrapartida aos recursos empregados para sua obtenção". A eficiência atingida contribui, de forma evolutiva, para o desempenho organizacional com intenção de atender satisfatoriamente às necessidades dos envolvidos, além de ser um artefato de monitoramento do desempenho. Nessa premissa de eficiência que Varian (1992), Ferreira, Gonçalves e Braga (2007), Trindade, Ferreira Filho e Bialoskorski Neto (2008), Rosalem et al (2010), Almada et al. (2011) destacam, as cooperativas de crédito alinham-se à necessidade de gerar eficiência em suas atividades, proporcionando aos cooperados, rendimentos aos seus investimentos ou condições de financiamento, no acesso aos produtos e serviços pertinentes na atividade desenvolvida.

Conforme Fried, Lovell e Eukaut (1993), as cooperativas de crédito assemelham-se às cooperativas de produção por adquirirem recursos de seus associados, e às cooperativas de consumo por emprestar seus recursos aos cooperados. Sendo assim, uma vez que as cooperativas são de propriedade e operadas por seus membros, seu objetivo deve ser voltado a maximizar os serviços financeiros a eles prestados (FRIED; LOVELL; EUCKAUT, 1993).

De acordo com Meurer e Marcon (2011) os cooperados, de modo geral, esperam um retorno sobre o capital social investido ao mesmo tempo em que esperam por um serviço de qualidade, com menor custo em relação ao praticado pelo mercado. Nesse sentido, percebe-se a importância da eficiência no processo de gestão que contribua para o aumento no desempenho econômico-financeiro da cooperativa a fim de atender às necessidades e aos objetivos de seus cooperados preocupados com os recursos financeiros sob gestão cooperativada.

Em relação à avaliação econômico-financeira as cooperativas de crédito necessitam de um grupo de indicadores que possam ser utilizados na análise de seu desempenho, e que acima de tudo, possam representar adequadamente as particularidades destas organizações. Nesse contexto, o World Council of Credit Unions (WOCCU) desenvolveu o PEARLS, para atender às particularidades das cooperativas de crédito (RICHARDSON, 2002; BRESSAN et al., 2011a; BRESSAN et al., 2011b).

Bressan et al. (2011a), destacaram indicadores contábeis-financeiros inéditos obedecendo às orientações do Método PEARLS, criado pelo WOCCU. De acordo com o WOCCU (2013) esse modelo é utilizado em vários países, e até então não havia sido pesquisado no Brasil, pela necessidade de uma adaptação ao ambiente nacional.

Algumas pesquisas têm adotado o método PEARLS. Em âmbito nacional destacam-se as de Bressan et al. (2008); Bressan et al. (2011b); Bressan et al., (2011c), as quais voltaram-se a identificar a insolvência em cooperativas de crédito. No que se refere ao contexto internacional, o PEARLS destaca-se nos estudos de Branch, Richardson e Mukasa (1998), Kirkpatrick e Maimbo (2002), Richardson (2008). Há também estudos voltados a análise da eficiência no desempenho de cooperativas, porém, a partir de indicadores tradicionais. Neste contexto, encontram-se os estudos de Ferreira, Gonçalves e Braga (2007) e Jayamaha e Mula (2007).

Diante do exposto, considerando a importância do desempenho econômico-financeiro, bem como sua obtenção com eficiência, para que as cooperativas de crédito possam atender aos seus objetivos em prol do benefício aos seus cooperados, formulou-se a seguinte questão de pesquisa: Qual a eficiência global no desempenho econômico-financeiro de cooperativas de crédito brasileiras? Visando atender ao problema proposto o objetivo desta pesquisa consiste em verificar a eficiência global no desempenho econômico-financeiro de cooperativas de crédito brasileiras. Justifica-se esta pesquisa pela importância das cooperativas de crédito, quer seja pelo papel que desempenham junto aos seus cooperados, ou pela sua representatividade, pois apesar de representar apenas $4,21 \%$ do volume de depósitos do sistema financeiro nacional, o cooperativismo de crédito está em $6^{\text {a }}$ lugar no ranking das maiores instituições financeiras do país, e, sobretudo, por atender mais de 6 milhões de associados em todo o Brasil (BACEN, 2014). Contribui com as cooperativas de crédito, pois proporciona um mecanismo de análise sobre a eficiência de sua estrutura financeira e seu desempenho, e, com os cooperados, bem como a comunidade em geral, pois proporciona uma visão sobre o desempenho global das cooperativas.

\section{DESEMPENHO ECONÔMICO-FINANCEIRO DE COOPERATIVAS}

Para Froman (1935) a atividade das cooperativas consiste na proteção dos fundos dos seus quotistas 
e depositantes, em troca de empréstimos desses fundos para outros cooperados. São organizações que buscam atender seus membros por meio de poupança, quando da disponibilidade e vontade destes em poupar seus recursos, ou por meio de empréstimos a eles para atender suas necessidades financeiras (CLARK, 1944).

A forma e a eficiência do funcionamento das cooperativas de crédito têm reduzido muitos dos altos custos de instituições que operam pequenos empréstimos. Também, eliminou a investigação do risco de empréstimos aos que necessitam de pequenos montantes por causa do vínculo de interesse entre os cooperados (ROSENBERG, 1950).

As sociedades cooperativas são reconhecidas como entidades sem fins lucrativos. Smith (1984) destaca que as cooperativas de crédito também obedecem esse preceito e são orientadas para serviços em concorrência com as demais instituições financeiras. Goddard, Mckillop e Wilson (2008) ressaltam que a principal força das cooperativas está fundamentada em sua filosofia e objetivos, e, de modo geral, no mundo todo as cooperativas de crédito demonstram eficácia quanto aos princípios cooperativos na gestão dos assuntos financeiros de milhões de pessoas.

Mulinari e Ritterbuch (2013) preconizam que o objetivo principal das cooperativas de crédito, assim como nos demais tipos de cooperativas, está fundamentado na cooperação mútua, são importantes à sociedade, pois disponibilizam seus produtos e serviços com maior facilidade e menor custo. Nesse sentido, torna-se fundamental que as cooperativas de crédito apresentem bom desempenho para melhor atender as necessidades dos cooperados.

Por meio dos índices é possível representar as relações entre as contas das demonstrações financeiras, fornecendo informações de forma direta sobre o desempenho das organizações, e a análise destes normalmente se dá a partir de determinadas características, como liquidez, estrutura de capital e rentabilidade (SILVA, 2001).

O estudo desenvolvido por Lerman e Parliament (1991) para medir desempenho, identificou que as grandes cooperativas regionais são mais eficientes empenhando seus ativos para gerar vendas, enquanto que as pequenas apresentam maior rentabilidade. A diminuição da rentabilidade mostrou-se semelhante às taxas para as pequenas e grandes cooperativas, enquanto que a variação da eficiência e da alavancagem tomava direções opostas.

Uma análise em cooperativas de crédito equatorianas, desenvolvida por Branch e Richardson (1998), a partir da utilização do PEARLS, indicou que as cooperativas de créditos acumularam provisões suficientes para créditos de liquidação duvidosa, melhoraram sua estrutura financeira, diminuíram seus ativos não rentáveis, conseguiram mais recursos para atender as atividades fins, houve aumento dos requisitos das reserva de liquidez e foram minimizadas as ociosidades dos fundos.

A partir da utilização do DEA, Fukuyama, Guerra e Weber (1999) analisaram o desempenho das cooperativas de crédito no Japão e constataram que as cooperativas de crédito estrangeiras foram mais eficazes que as nacionais, a medição foi feita pelos empréstimos e depósitos. No entanto, destacaram que as cooperativas de crédito são instituições importantes nas finanças japonesas.

De acordo com Ferreira, Gonçalves e Braga (2007) as cooperativas de crédito mais eficientes desempenham melhor seu papel socioeconômico, pois promovem a desintermediação financeira, que torna o diferencial entre as taxas de captação e empréstimos; aumenta a capacidade de gerar sobras, que representam o retorno excedente, podendo ser distribuído ou reinvestido na cooperativa, além de aumentar o volume de crédito concedido, seu recurso mais lucrativo

Goddard, Mckillop e Wilson (2008) investigaram o impacto da diversificação de receitas sobre o desempenho financeiro em cooperativas de crédito dos Estados Unidos. Eles detectaram que o volume de receitas geradas fora da atividade fim aumentou significativamente nos últimos anos. Cooperativas de crédito menores devem evitar diversificação e continuar a operar como órgão de poupança e instituições de crédito, enquanto que as grandes devem explorar novas oportunidades de produtos em torno de sua principal especialidade.

Dambros, Lima e Figueiredo (2009) analisaram os níveis de eficiência das cooperativas de crédito do Sistema Sicredi no Estado do Paraná, na aplicação de crédito e na rentabilidade econômica e liquidez. Os resultados mostraram, pelo índice de desempenho econômico do crédito, que as cooperativas com melhores desempenhos foram também aquelas que apresentaram resultados mais equilibrados, conciliando elevados volumes de crédito com captação de recursos de maneira dinâmica e com menores custos.

Carvalho et al. (2009) realizaram estudo para avaliar os fatores relacionados à mortalidade de cooperativas de crédito e verificar se sua longevidade está relacionada aos mesmos fatores. Constataram que a duração e mortalidade dessas entidades estão relacionadas ao seu tamanho e sua eficiência operacional, resultado que sugere como forma de reduzir a mortalidade dessas entidades o fortalecimento da intercooperação e a busca de maior eficiência operacional por parte das cooperativas de crédito brasileiras. 
O estudo de Bressan, Lopes e Menezes (2013) avaliou o desempenho das cooperativas de crédito filiadas ao Sicoob. Os resultados indicaram que há limitações de eficiência das cooperativas e a necessidade de conjugar esforços no sentido de buscar o compromisso das cooperativas de crédito para maximizarem seus resultados, em decorrência de uma exploração eficaz dos seus recursos com o intuito de maximizar seus resultados e atingir maiores padrões de eficiência.

\section{MÉTODO PEARLS}

As organizações cooperativas possuem uma série de complexidades administrativas, que acarretam em desafios para criar mecanismos de gestão compatíveis com essas complexidades, atendem as exigências estabelecidas pelo Banco Central e ainda atendem os seus princípios doutrinários (BRESSAN et al. 2011a).

Ao longo do tempo foram criados vários índices financeiros e regras empíricas para as instituições financeiras em todo o mundo, mas poucos deles foram consolidados em um programa de avaliação capaz de medir os componentes de forma individual, bem como, no sistema como um todo (RICHARDSON, 2002; ZHINGRE, 2012).

Buscando proporcionar um mecanismo capaz de medir e analisar o desempenho financeiro das cooperativas de crédito do mundo todo, o WOCCU (Conselho mundial das cooperativas de crédito) desenvolveu o método PEARLS (CHRISTELLE, 2009). Conforme Bressan et al. (2008, p. 3) o acrônimo representa os seguintes grupos: "Protection (Proteção), Effective financial structure (Estrutura Financeira Efetiva), Assets quality (Qualidade de Ativos), Rates of return and costs (Taxas de retorno e custos), Liquidity (Liquidez), e Signs of growth (Sinais de crescimento)".

De acordo com Chistelle (2009), na década de 80, o WOCCU procurou adaptar as cooperativas de crédito ao método CAMELS, acrônimo para as dimensões de desempenho usado para avaliar crédito cooperado Fried; Lovell; Yaisawarng (1999), que representa: Capital (Capital); Assets (Ativos); Management (Gestão); Earnings (Rentabilidade); Liquidity (Liquidez) e Sensitivity to price risks (Sensibilidade) (BRESSAN et al., 2008) com destaque para um conjunto de indicadores para medir desempenho e monitorar instituições financeiras. Mas, para tanto, havia a necessidade de uma série de mudanças, e por conta desta série de mudanças foi criada a metodologia PEARLS, que passou a ser designada como um instrumento de gestão e mais tarde tornou-se um mecanismo de supervisão mundialmente utilizado.

Segundo Zhingre (2012) a WOCCU destacou, inicialmente, duas deficiências que limitam sua eficácia. A primeira deve-se ao fato de que o modelo não contempla uma avaliação da estrutura financeira geral do balanço, pois a estrutura do balanço tem um impacto direto sobre a eficiência e rentabilidade, que são fatores importantes para que as cooperativas de crédito possam realizar operações eficazes e sustentáveis em um ambiente competitivo. A segunda deficiência destacada por Zhingre (2012) que aporta sobre o sistema CAMELS, é que este não considera as taxas de crescimento, fundamentais para resolver problemas como os decorrentes da desvalorização da moeda e a inflação. Sobretudo, em um ambiente macroeconômico adverso, as cooperativas de crédito precisam manter um crescimento elevado para preservar o valor de seus ativos.

De acordo com Richardson (2002), desde 1990 o WOCCU passou a utilizar um conjunto de índices financeiros, conhecido como PEARLS. Esse método difere do CAMELS por ter sido concebido como uma ferramenta de gestão, e mais tarde se tornou um mecanismo de supervisão eficaz.

O método PEARLS é importante para monitorar o desempenho da cooperativa de crédito, é uma ferramenta de gestão que vai além da mera identificação de problemas e ajuda a gestão a encontrar soluções para suas deficiências institucionais, pois proporciona a identificação das deficiências e suas devidas causas (BRESSAN et al., 2008; ZHINGRE, 2012).

Para Bressan et al. (2011a) o uso do método PEARLS permite a identificação de cooperativas com estrutura de capital fraca e também a identificação das causas do problema. Zhingre (2012) ressalta que o PEARLS permite uma identificação rápida e precisa das áreas problemáticas das cooperativas, e a partir disso, que os ajustes possam ser feitos antes que os problemas se tornem mais graves. Para a autora, trata-se de um sistema de alerta precoce que gera valiosas informações gerencias.

O método PEARLS estabelecido pelo WOCCU representa um conjunto de 45 índices financeiros distribuídos nas seis áreas que o compõem, é baseado no desempenho financeiro e sua análise é essencialmente 
quantitativa, ignorando quaisquer dados qualitativos, pois, de acordo com o WOCCU, o desempenho global da instituição é melhor representado e traduzido em resultados quantitativos (CHRISTELLE, 2009).

Cada letra do acrônimo PEARLS está voltada a um aspecto diferente e mais crítico das cooperativas de crédito. A seguir está representado o que reporta cada um dos aspectos segundo o WOCCU e conforme apresentado por Richardson (2002) e Zhingre (2012), tendo sua forma de mensuração apresentada no Quadro 1, Indicadores analisados para determinar a eficiência das cooperativas:

$$
\text { a) } \quad \mathrm{P}=\text { Proteção }
$$

A proteção adequada dos ativos é um princípio básico do novo modelo de cooperativa de crédito. É medida de duas formas: 1) comparando a adequação das provisões para créditos de liquidação duvidosa em relação ao montante de empréstimos inadimplentes e 2) comparando as provisões para perdas em investimentos com o valor total dos investimentos não-regulamentados.

$$
\text { b) } \quad \mathrm{E}=\text { Estrutura Financeira Eficiente }
$$

A estrutura financeira da cooperativa de crédito é o fator mais importante para determinar o potencial de crescimento, a capacidade de ganhos e a força financeira global. O método PEARLS permite a mensuração da estrutura que proporciona um direcionador das ações dos gestores financeiros.

c) $\quad \mathrm{A}=$ Qualidade dos ativos

Um ativo não produtivo ou não lucrativo é aquele que não gera renda. O excesso de ativos não remunerados afetam o resultado da cooperativa de crédito de uma forma negativa. Para identificar o impacto dos ativos não remunerados são utilizados os indicadores de inadimplência, percentuais de ativos não operacionais e o financiamento de ativos não operacionais.

d) $\quad \mathrm{R}=$ Taxas de Retorno e Custos

O método PEARLS segrega todos os componentes essenciais das sobras líquidas para ajudar a gestão a calcular os rendimentos de investimento e avaliar as despesas operacionais. Dessa forma, demonstra o seu valor como uma ferramenta de gestão. Ao contrário de outros sistemas em que os rendimentos são calculados com base na média de ativos, o PEARLS calcula os rendimentos com base em investimentos reais pendentes. Essa metodologia auxilia a gestão na determinação de quais investimentos são os mais rentáveis. Ao segregar as receitas e despesas o método PEARLS pode identificar com precisão as razões pelas quais uma cooperativa de crédito não está produzindo lucro líquido suficiente.

e) $\quad \mathrm{L}=$ Liquidez

A gestão eficaz da liquidez se torna uma habilidade muito importante quando a cooperativa de crédito troca sua estrutura financeira baseada em quotas dos cooperados (capital próprio) pela volatilidade dos depósitos de poupança (capital de terceiros). Em muitas ações seguindo o tradicional modelo, as quotas de capital praticamente não possuem liquidez e grande parte dos empréstimos externos tem um longo período de retorno, com isso, há pouco incentivo para manter as reservas de liquidez. A liquidez é tradicionalmente vista em termos de caixa disponível para emprestar - uma variável exclusivamente controlada pela cooperativa de crédito. Com a introdução de depósitos de poupança de liquidez imediata, o conceito de liquidez é radicalmente alterado. A liquidez agora se refere ao caixa necessário para retiradas - uma variável que a cooperativa de crédito não pode mais controlar.

$$
\text { f) } \quad \mathrm{S}=\text { Sinais de crescimento }
$$

A única maneira bem sucedida para manter os ativos valorizados é pelo crescimento forte e acelerado de ativos, acompanhado de rentabilidade sustentada. O crescimento por si só não é suficiente. A vantagem do método PEARLS é que ele liga o crescimento à rentabilidade, bem como a outras áreas-chave, avaliando a força do sistema como um todo. O PEARLS foi adaptado ao contexto brasileiro por Bressan et al. (2011a), compreendendo um grupo de 39 indicadores distribuídos nos seis grupos do PEARLS, sendo esta a estrutura adotada para realização desta pesquisa.

\section{PROCEDIMENTOS METODOLÓGICOS}

Esta pesquisa caracteriza-se como descritiva em relação aos seus objetivos. Quanto à coleta e ao 
tratamento dos dados adotou-se procedimento documental, e com abordagem predominantemente quantitativa na análise dos dados.

Adotaram-se como população todas as cooperativas de crédito brasileiras atuantes, de acordo com dados do Banco Central do Brasil (BACEN). No entanto, a análise parte de uma amostra intencional composta pelas vinte (25) maiores cooperativas de crédito brasileiras, a partir do ranking divulgado pelo BACEN (2013) com dados de 30 de junho de 2013 .

O período analisado é de 2008 a 2012. Todas as cooperativas inicialmente selecionadas na amostra apresentaram as informações necessárias, não havendo necessidade de exclusão de nenhuma cooperativa. A definição para o período de análise de cinco anos foi tomada com base de estudos que analisaram o desempenho em períodos de até cinco anos, como os de Bressan, Braga e Bressan (2011), Ferreira, Gonçalves e Braga (2007), Barroso (2009), Agarwal e Sinha (2010), Christelle (2009), Zhingre (2012).

Os dados necessários para a elaboração da análise proposta foram coletados junto ao BACEN que disponibiliza as informações contábeis de todas as instituições financeiras. Os referidos dados constam nos Balancetes e Balanços Patrimoniais das instituições divulgados pelo BACEN e elaborados de acordo com o Plano de Contas das Instituições do Sistema Financeiro Nacional (COSIF).

Para a análise dos dados foi adotado o conjunto de indicadores do PEARLS, adaptado ao contexto brasileiro, composto por 39 indicadores. No entanto, devido à indisponibilidade de informações foi possível utilizar apenas 37 indicadores. Esse conjunto de indicadores foi submetido à Análise de Componentes Principais (ACP) para selecionar aqueles com a maior carga informacional, restando um conjunto de 20 indicadores, assim distribuídos:

\begin{tabular}{|c|c|c|}
\hline Grupo & Indicador & Proxy \\
\hline \multirow{3}{*}{ Proteção } & P1 & Provisão para liquidação duvidosa sob operações de crédito (PCLD)/ Carteira Classificada Total \\
\hline & P2 & Operações de crédito vencidas /Carteira Classificada Total \\
\hline & P4 & $\begin{array}{l}\text { Operações de Risco nível D até H - Percentual de Provisão Estimado nível D até H / PL } \\
\text { Ajustado }\end{array}$ \\
\hline \multirow{4}{*}{$\begin{array}{l}\text { Estrutura } \\
\text { financeira } \\
\text { eficiente }\end{array}$} & E1 & Operações de crédito líquidas/ Ativo Total \\
\hline & E2 & Investimentos Financeiros/ Ativo Total \\
\hline & E5 & Renda de intermediação financeira/ Ativo Total Médio \\
\hline & E6 & Ativo Total / Patrimônio Líquido Ajustado \\
\hline \multirow{2}{*}{$\begin{array}{l}\text { Qualidade } \\
\text { dos ativos }\end{array}$} & A1 & Ativo Permanente + Ativos não direcionados com atividade fim da cooperativa/ PL Ajustado \\
\hline & $\mathrm{A} 2$ & Imobilização = Ativo Permanente / Patrimônio Líquido Ajustado \\
\hline \multirow{7}{*}{$\begin{array}{l}\text { Taxas de } \\
\text { retorno e } \\
\text { custos }\end{array}$} & $\mathrm{R} 1$ & Rendas de operações de crédito /Operações de crédito média \\
\hline & R5 & Margem Bruta/Ativo Total Médio \\
\hline & R6 & Despesas Operacionais/Ativo Total Médio \\
\hline & R9 & Resultado da Intermediação Financeira / Receita Operacional \\
\hline & $\mathrm{R} 10$ & Sobras / Receita Operacional \\
\hline & $\mathrm{R} 12$ & Despesas de Gestão / Despesas Administrativas \\
\hline & $\mathrm{R} 13$ & Despesas Administrativas / Ativo total médio \\
\hline Liquidez & L2 & Ativos de curto prazo / Depósitos totais \\
\hline \multirow{3}{*}{$\begin{array}{l}\text { Sinais de } \\
\text { crescimento }\end{array}$} & S7 & Crescimento do Patrimônio Líquido Ajustado $=($ PLA do mês corrente/ PLA do mês anterior $)-1$ \\
\hline & S8 & Crescimento do Ativo total $=($ AT do mês corrente $/$ AT do mês anterior $)-1$ \\
\hline & S9 & $\begin{array}{l}\text { Crescimento das operações de crédito }=(\text { Operações de crédito do ano corrente/ Operações de } \\
\text { crédito do ano anterior) }-1\end{array}$ \\
\hline
\end{tabular}

Quadro 1. Indicadores analisados para determinar a eficiência das cooperativas Fonte: Elaborado pelos autores.

A eficiência no desempenho econômico-financeiro das cooperativas de crédito foi determinada por meio de análise multicritério TOPSIS, acrônimo de Technique for Order Preference by Similarity to Ideal Solution, desenvolvido por Hwang e Yoon em 1981 (ERTUGRUL; NARAKASOGLU, 2009; WU; TZENG; CHEN, 2009; BULGURCU, 2012). O modelo, conforme preconiza Wu, Tzeng e Chen (2009), estrutura-se no conceito de que as melhores escolhas ou alternativas devem ser a distância mais curta entre a solução ideal positiva, e a mais distante da solução negativa ideal. O método TOPSIS considera a distância entre ambos os lados para classificação dos 
elementos (BULGURCU, 2012).

A solução ideal é uma solução considerada positiva que maximize o critério de benefícios e minimize os critérios de custo, já que a solução ideal negativa maximiza os critérios de custo e minimiza os critérios de benefícios (ERTUGRUL; NARAKASOGLU, 2009). Em suma, a solução considerada ideal positiva é constituída por todos os melhores valores possíveis, já a solução ideal negativa consiste de todos os piores valores atingíveis (ERTUGRUL; NARAKASOGLU, 2009). Assim, segundo Wu, Tzeng e Chen (2009), a alternativa mais perfeita não só deve ser a distância mais curta a partir da solução ideal positiva, mas também deve ser a maior distância a partir da solução ideal negativa.

O método TOPSIS atribui um score a partir do cálculo, em um determinado grupo de informações, da distância entre o ponto ideal e o não ideal. Assim quanto menor for a distância entre a observação e o ponto ideal para aquele conjunto de informações, maior será o score. Por outro lado, quanto mais próximo do ponto não ideal, também conhecido como anti-ideal, menor será o score daquela observação.

Inicialmente, é calculado o TOPSIS para cada um dos grupos de indicadores do PEARLS, em cada um dos períodos. A partir do score gerado passa a ser calculado um TOPSIS para cada período. Para isso, o número de indicadores correspondentes a cada grupo do PEARLS é atribuído como o peso de cada um dos scores. Em seguida, a partir do score gerado por período, foi calculado um novo TOPSIS visando determinar a eficiência global para as cooperativas de crédito analisadas.

Alguns indicadores são melhores, quanto maiores forem seus índices e em outros ocorre o inverso, pois quanto menor o índice melhor. Então para o cálculo do TOPSIS, e para trabalhá-los no mesmo contexto, os que são melhores quando menores, foram subtraídos de uma mesma base para proporcionar sua inversão, de modo que todos possam ser interpretados sob o contexto de que quanto maior o índice melhor. Esse procedimento não compromete o resultado da análise.

\section{ANÁLISE E INTERPRETAÇÃO DOS RESULTADOS}

A análise da eficiência foi fundamentada sobre os índices apresentados pelas cooperativas em cada um dos indicadores, seguindo, para tanto, as recomendações do WOCCU, sobre os valores considerados adequados para cada indicador, apresentados por Richardson (2002) e Bressan et al. (2011a). Com isso, partiu-se do contexto de que as cooperativas mais eficientes são aquelas com os índices mais próximos ao valor "ideal" recomendado, do outro lado encontram-se as menos eficientes.

Visando determinar a eficiência global no desempenho econômico-financeiro de cooperativas de crédito brasileiras, inicialmente foi encontrado um score de eficiência para cada um dos grupos de indicadores do PEARLS, em cada período da análise. Definidos os scores em cada grupo de indicadores para cada cooperativa nos cinco períodos, foi elaborado o cálculo do TOPSIS por período a partir do score gerado por grupo de indicadores.

Adotou-se o número de indicadores em cada grupo do PEARLS como peso de cada grupo na determinação do TOPSIS do período, com vistas a contemplar igualmente os indicadores utilizados na análise. Assim, a Tabela 1, foi elaborada para demonstrar a eficiência das cooperativas analisadas em cada um dos períodos.

Tabela 1. TOPSIS das cooperativas por período analisado

\begin{tabular}{l|c|c|c|c|c|c|c|c|c|c}
\hline Cooperativas & $\mathbf{2 0 0 8}$ & Pos. & $\mathbf{2 0 0 9}$ & Pos. & $\mathbf{2 0 1 0}$ & Pos. & $\mathbf{2 0 1 1}$ & Pos. & $\mathbf{2 0 1 2}$ & Pos. \\
\hline Coopercítrus & 0,659 & 4 & 0,648 & 1 & 0,633 & 7 & 0,493 & 8 & 0,531 & 9 \\
\hline Sicoob Cocred & 0,421 & 14 & 0,359 & 20 & 0,448 & 19 & 0,378 & 17 & 0,393 & 18 \\
\hline Viacredi & 0,582 & 6 & 0,616 & 4 & 0,444 & 20 & 0,617 & 1 & 0,531 & 10 \\
\hline Sicredi C. Norte MT & 0,491 & 10 & 0,434 & 12 & 0,547 & 11 & 0,415 & 12 & 0,467 & 14 \\
\hline Sicoob Cooperforte & 0,664 & 3 & 0,605 & 5 & 0,689 & 1 & 0,559 & 3 & 0,556 & 6 \\
\hline Sicredi União PR & 0,363 & 22 & 0,299 & 23 & 0,433 & 21 & 0,324 & 19 & 0,392 & 19 \\
\hline Sicredi Pioneira RS & 0,434 & 13 & 0,364 & 19 & 0,475 & 17 & 0,316 & 20 & 0,346 & 23 \\
\hline Credicoamo & 0,696 & 1 & 0,618 & 3 & 0,686 & 2 & 0,550 & 4 & 0,574 & 5 \\
\hline Vanguarda PR/SP & 0,382 & 20 & 0,376 & 17 & 0,481 & 15 & 0,376 & 18 & 0,425 & 16 \\
\hline
\end{tabular}


Tabela 1. TOPSIS das cooperativas por período analisado (continuação)

\begin{tabular}{l|c|c|c|c|c|c|c|c|c|c}
\hline Cooperativas & $\mathbf{2 0 0 8}$ & Pos. & $\mathbf{2 0 0 9}$ & Pos. & $\mathbf{2 0 1 0}$ & Pos. & $\mathbf{2 0 1 1}$ & Pos. & $\mathbf{2 0 1 2}$ & Pos. \\
\hline Sicoob Credicom & 0,365 & 21 & 0,375 & 18 & 0,477 & 16 & 0,301 & 21 & 0,358 & 20 \\
\hline Sicoob Coopecredi & 0,518 & 9 & 0,445 & 11 & 0,556 & 10 & 0,425 & 11 & 0,414 & 17 \\
\hline Sicredi União RS & 0,397 & 18 & 0,383 & 16 & 0,386 & 25 & 0,293 & 22 & 0,341 & 24 \\
\hline Sicredi R. Vales RS & 0,332 & 24 & 0,295 & 24 & 0,387 & 24 & 0,251 & 25 & 0,279 & 25 \\
\hline Sicredi Celeiro MT & 0,419 & 16 & 0,385 & 15 & 0,518 & 12 & 0,384 & 16 & 0,492 & 12 \\
\hline Uniprime Norte PR & 0,600 & 5 & 0,547 & 8 & 0,621 & 8 & 0,464 & 9 & 0,498 & 11 \\
\hline Sicredi Serrana RS & 0,342 & 23 & 0,327 & 22 & 0,417 & 22 & 0,282 & 23 & 0,349 & 22 \\
\hline Crediconai & 0,482 & 12 & 0,545 & 9 & 0,588 & 9 & 0,464 & 10 & 0,533 & 8 \\
\hline Sicredi P. Gaúcho & 0,421 & 15 & 0,345 & 21 & 0,515 & 13 & 0,401 & 14 & 0,429 & 15 \\
\hline Sicredi Centro Sul & 0,407 & 17 & 0,409 & 13 & 0,502 & 14 & 0,405 & 13 & 0,583 & 2 \\
\hline Unicred Centro Bras. & 0,537 & 8 & 0,590 & 6 & 0,644 & 6 & 0,505 & 6 & 0,537 & 7 \\
\hline Sicredi V. Do Piriqui & 0,390 & 19 & 0,389 & 14 & 0,462 & 18 & 0,389 & 15 & 0,490 & 13 \\
\hline Sicredi Norte RS/SC & 0,306 & 25 & 0,279 & 25 & 0,399 & 23 & 0,270 & 24 & 0,353 & 21 \\
\hline Unicred Florianóplis & 0,538 & 7 & 0,520 & 10 & 0,650 & 5 & 0,501 & 7 & 0,574 & 4 \\
\hline Sicoob Maxicrédito & 0,486 & 11 & 0,576 & 7 & 0,665 & 4 & 0,541 & 5 & 0,577 & 3 \\
\hline Unicred J. Pessoa & 0,676 & 2 & 0,624 & 2 & 0,669 & 3 & 0,575 & 2 & 0,623 & 1 \\
\hline
\end{tabular}

Fonte: Dados da pesquisa.

Na Tabela 1 cada período da análise é demonstrado em uma coluna, constando o score de eficiência atingido por cada cooperativa, bem como a sua posição em relação às demais cooperativas que compõe a amostra analisada.

O método TOPSIS considera os maiores scores de cada período como o cenário ideal para o conjunto a ser analisado, bem como todos os menores para determinar o anti-ideal, e o score é determinado pela distância do conjunto (cooperativa) analisado em relação às duas extremidades. Quanto maior o score apresentado pelas cooperativas maior a sua eficiência, visto que mais se aproximam do ponto ideal $(1,000)$ e possuem a menor distância para o ponto máximo. Por outro lado, os menores scores remetem às cooperativas com menor eficiência entre o grupo analisado, pois são as mais distantes do ponto ideal, ou seja, são as que mais se aproximam do ponto considerado anti-ideal $(0,000)$.

Nesse sentido, destacam-se como as mais eficientes, por apresentarem os maiores scores, a Credicoamo em 2008, a Coopercítrus em 2009, a Sicoob Cooperforte em 2010, a Viacredi em 2011 e a Unicredi João Pessoa no período de 2012. Na outra extremidade, como as menos eficientes da amostra por período analisado destacam-se a Sicredi Norte RS/SC nos períodos de 2008 e 2009, a Sicredi União RS em 2010 e a Sicredi Região dos Vales em 2011e 2012.

Os scores de eficiência apresentados pelas cooperativas é utilizado para calcular um novo TOPSIS e determinar sua eficiência considerando todo o período analisado, a partir do novo score gerado. No entanto, vale destacar que o resultado não indica o quão eficientes são as cooperativas, mas sim, quais são as mais ou menos eficientes entre as cooperativas que compõe a amostra desta pesquisa. Nesse contexto, a Tabela 2 retrata os resultados do TOPSIS elaborado sobre o score apresentado pelas cooperativas de crédito em cada um dos períodos.

Tabela 2. Eficiência das cooperativas de crédito

\begin{tabular}{l|l|c|c|c|c}
\hline Pos. & Cooperativa & Pos. BACEN & Dist. Ideal & Dist. Não Ideal & Score TOPSIS \\
\hline $1^{\mathrm{a}}$ & Unicred J. Pessoa & $25^{\mathrm{a}}$ & 0,0558 & 0,6650 & 0,9226 \\
\hline $2^{\mathrm{a}}$ & Credicoamo & $8^{\mathrm{a}}$ & 0,0881 & 0,6687 & 0,8836 \\
\hline $3^{\mathrm{a}}$ & Sicoob Cooperforte & $5^{\mathrm{a}}$ & 0,1036 & 0,6494 & 0,8624 \\
\hline $4^{\mathrm{a}}$ & Coopercítrus & $1^{\mathrm{a}}$ & 0,1683 & 0,6174 & 0,7858 \\
\hline $5^{\mathrm{a}}$ & Unicred Centro Bras. & $20^{\mathrm{a}}$ & 0,2252 & 0,5306 & 0,7020 \\
\hline $6^{\mathrm{a}}$ & Sicoob Maxicrédito & $24^{\mathrm{a}}$ & 0,2408 & 0,5322 & 0,6885 \\
\hline $7^{\mathrm{a}}$ & Unicred Florianóplis & $23^{\mathrm{a}}$ & 0,2427 & 0,4944 & 0,6707 \\
\hline $8^{\mathrm{a}}$ & Uniprime Norte PR & $15^{\mathrm{a}}$ & 0,2508 & 0,5095 & 0,6702 \\
\hline
\end{tabular}


Tabela 2. Eficiência das cooperativas de crédito (continuação)

\begin{tabular}{l|l|c|c|c|c}
\hline Pos. & Cooperativa & Pos. BACEN & Dist. Ideal & Dist. Não Ideal & Score TOPSIS \\
\hline $9^{\mathrm{a}}$ & Viacredi & $3^{\mathrm{a}}$ & 0,2874 & 0,5725 & 0,6657 \\
\hline $10^{\mathrm{a}}$ & Crediconai & $17^{\mathrm{a}}$ & 0,3134 & 0,4340 & 0,5806 \\
\hline $11^{\mathrm{a}}$ & Sicoob Coopecredi & $11^{\mathrm{a}}$ & 0,4136 & 0,3638 & 0,4679 \\
\hline $12^{\mathrm{a}}$ & Sicredi C. Norte MT & $4^{\mathrm{a}}$ & 0,4161 & 0,3340 & 0,4453 \\
\hline $13^{\mathrm{a}}$ & Sicredi Centro Sul & $19^{\mathrm{a}}$ & 0,4714 & 0,2542 & 0,3503 \\
\hline $14^{\mathrm{a}}$ & Sicredi Celeiro MT & $14^{\mathrm{a}}$ & 0,4963 & 0,2440 & 0,3296 \\
\hline $15^{\mathrm{a}}$ & Sicredi P. Gaúcho & $18^{\mathrm{a}}$ & 0,5310 & 0,2386 & 0,3100 \\
\hline $16^{\mathrm{a}}$ & Sicredi V. Do Piriqui & $21^{\mathrm{a}}$ & 0,5316 & 0,2100 & 0,2832 \\
\hline $17^{\mathrm{a}}$ & Vanguarda PR/SP & $9^{\mathrm{a}}$ & 0,5598 & 0,2002 & 0,2634 \\
\hline $18^{\mathrm{a}}$ & Sicoob Cocred & $2^{\mathrm{a}}$ & 0,5723 & 0,1998 & 0,2588 \\
\hline 19 & Sicredi Pioneira RS & $7^{\mathrm{a}}$ & 0,6020 & 0,1900 & 0,2399 \\
\hline $20^{\mathrm{a}}$ & Sicoob Credicom & $10^{\mathrm{a}}$ & 0,6318 & 0,1539 & 0,1959 \\
\hline $21^{\mathrm{a}}$ & Sicredi União RS & $12^{\mathrm{a}}$ & 0,6602 & 0,1454 & 0,1805 \\
\hline $22^{\mathrm{a}}$ & Sicredi União PR & $6^{\mathrm{a}}$ & 0,6610 & 0,1069 & 0,1392 \\
\hline $23^{\mathrm{a}}$ & Sicredi Serrana RS & $16^{\mathrm{a}}$ & 0,6996 & 0,0750 & 0,0968 \\
\hline $24^{\mathrm{a}}$ & Sicredi R. Vales RS & $13^{\mathrm{a}}$ & 0,7750 & 0,0312 & 0,0387 \\
\hline $25^{\mathrm{a}}$ & Sicredi Norte RS/SC & $22^{\mathrm{a}}$ & 0,7524 & 0,0235 & 0,0303 \\
\hline
\end{tabular}

Fonte: Dados da pesquisa.

A primeira e segunda colunas da Tabela 2 contemplam o conjunto de cooperativas analisadas nesta pesquisa, ordenadas de acordo com o score gerado pelo TOPSIS, partindo do maior para o menor. A terceira coluna mostra a posição de cada cooperativa de acordo com o ranking das maiores cooperativas de crédito brasileiras, divulgado pelo BACEN com data base de 30 de junho de 2013.

Na quarta coluna é apresentada a distância de cada cooperativa em relação ao cenário ideal, a partir dos índices apresentados nos períodos. A quinta coluna contempla a distância da cooperativa em relação ao ponto antiideal, também calculado a partir dos índices de cada cooperativa.

Por fim, na sexta coluna estão apresentados os scores das cooperativas. Quanto mais próximo ao ideal a cooperativa estiver, maior será o score, e quanto mais distante estiver, menor será. O score representa quais são as cooperativas mais ou menos eficientes dentro do grupo analisado, além de demonstrar a distância de eficiência entre elas.

Nesse contexto, a cooperativa que se mostrou mais eficiente nos períodos analisados é a Unicredi João Pessoa, com score de 0,9226. Apesar de apresentar o maior score ela não foi a melhor em todos os períodos, visto que existe distância para o ponto ideal. Para ser a melhor em todos os períodos a distância para o ideal deveria ser zero e o score igual a 1,000. Na sequência aparece a Coopercítrus, como a segunda cooperativa mais eficiente com score de 0,8836 , e a terceira mais eficiente é a Credicoamo $(0,8624)$. A análise pelo score possibilita uma melhor interpretação em relação à eficiência, pois permite verificar a distância entre as cooperativas, algo que não seria possível em caso de utilização de ranking sem score, somente pelas posições a distância seria igual entre as posições.

Essa situação pode ser observada nas três cooperativas mais eficientes, em que a distância da $1^{\text {a }}$ para a $2^{\mathrm{a}}(0,9226$ para 0,8836$)$ é relativamente maior do que da $2^{\mathrm{a}}$ para a $3^{\mathrm{a}}(0,8836$ para 0,8624$)$, indicando que a Coopercítus e a Credicoamo possuem estruturas econômico-financeiras mais parecidas. Esse fator pode ser observado também entre a Unicredi Florianópolis e a Uniprime Norte PR com scores ainda mais parecidos $(0,6707$ e 0,6702 ), indicando que essas cooperativas são praticamente idênticas em termos de estrutura econômicofinanceira.

Apesar das semelhanças, conforme apresentado, há situações de maior distância entre as posições, como observado entre a Crediconai na $10^{\mathrm{a}}$ posição $(0,5806)$ e a Sicoob Coopecredi na $11^{\mathrm{a}}$ posição $(0,4679)$. Essas distâncias maiores poderiam ser utilizadas para determinar os grupos de cooperativas que mais se assemelham. Nesse contexto, essas duas cooperativas podem ser utilizadas como parâmetro para o ponto de separação entre as cooperativas mais e menos eficientes da amostra, ficando 10 cooperativas como as mais eficientes e 15 como as 
menos eficientes.

$\mathrm{Na}$ extremidade das cooperativas menos eficientes estão a Sicredi Região dos Vales RS $(0,0387)$ e a Sicredi Norte RS/SC (0,0303). Embora tenham apresentado scores tão baixos, não podem ser designada como não eficientes. Pode-se caracterizá-las como as menos eficientes entre as cooperativas analisadas nesta pesquisa.

O estudo de Jayamaha e Mula (2007) também analisou a eficiência em cooperativas de crédito por meio do DEA, mas a partir de indicadores tradicionais. Os resultados indicaram uma relação entre a eficiência e as práticas financeiras adotadas pelas cooperativas, confirmando que as cooperativas mais eficientes são aquelas que adotam as melhores práticas financeiras. Nesse contexto foi desenvolvida a presente pesquisa, pois adotou-se como parâmetro para avaliar os índices o recomendado pelo WOCCU, conforme Richardson (2002) e Bressan et al. (2011a). Assim, as cooperativas mais eficientes são aquelas que apresentaram uma estrutura de índices mais adequada ao considerado ideal.

Agarwal e Sinha (2010) analisaram o desempenho financeiro em pequenas instituições financeiras na Índia, e destacaram a importância do desempenho eficiente para que essas instituições possam se manter no mercado, principalmente por não haver um órgão regulador para essas instituições. Os resultados indicaram diferentes desempenhos entre as instituições. No entanto, quando observadas por setor de atuação mostraram-se semelhantes em termos de desempenho, indicando que, mesmo sem um órgão regulador, as próprias instituições adotaram políticas semelhantes, fator que pode ter contribuído para sua sobrevivência ao longo dos anos.

Percebe-se, a partir dos resultados da presente pesquisa, que as cooperativas de crédito brasileiras, mesmo com o BACEN atuando como órgão regulador e o WOCCU recomendando padrões de estrutura econômicofinanceira, não estão apresentando desempenho econômico financeiro semelhante entre elas. Isso mostra a existência de políticas próprias de funcionamento, reflexo do poder de decisão de seus membros que decidem em prol de seus interesses e objetivos.

Rossel-Cambier (2010), em seu estudo realizado em pequenas instituições financeiras da América Latina e Caribe, identificou que a diversificação de serviços financeiros proporciona maior eficiência operacional e produtividade destas instituições, visto que envolvem vários setores da economia. No entanto, devem estar preparadas em termos de estrutura e recursos humanos para atender à complexidade da diversificação de serviços.

As cooperativas de crédito brasileiras, em geral, estão sob a forma de livre admissão de associados, o que possibilita a diversificação dos serviços prestados, pois seus cooperados demandam dos mais diversos tipos de serviços financeiros para satisfazer suas necessidades, possibilitando com isso maior eficiência operacional e produtividade. Isso contribui também à minimização dos riscos, uma vez que amplia o leque da produtividade.

Bressan, Lopez e Menezes (2013) avaliaram o desempenho de cooperativas de crédito brasileiras filiadas ao Sicoob, por meio do DEA, a partir de indicadores contábeis do PEARLS. Os resultados indicaram que há limitações de eficiência, menos de $10 \%$ das cooperativas analisadas mostraram-se eficientes. O tamanho e o tempo de existência não possuem relação com a eficiência das cooperativas, pois cooperativas com menos de um ano e pequenas, mostraram-se tão eficientes, quanto outras maiores e com mais tempo de existência.

A presente pesquisa foi realizada com as 25 maiores cooperativas de crédito brasileiras, as quais são filiadas a diversas redes. Com isso, foi possível perceber que o tamanho das cooperativas não está relacionado com sua eficiência, como pode ser observado na Unicred João Pessoa, que pelo BACEN ocupa a $25^{a}$ posição, mas que pelo modelo de análise aplicado, obteve a maior eficiência global entre as analisadas.

Isso mostra que a eficiência no desempenho econômico-financeiro das cooperativas de crédito independe do seu volume de ativos, número de cooperados, montante de receitas e outros, mas depende de sua política de funcionamento (captação e aplicação dos recursos) e principalmente da gestão eficiente desses recursos, que se refletem diretamente nos índices que determinam sua eficiência.

\section{CONCLUSÕES}

Com vistas a verificar a eficiência global no desempenho econômico-financeiro de cooperativas de crédito brasileiras, adotou-se o método TOPSIS, para determinar um score a partir do melhor e pior cenário para cada cooperativa. O score gerado não determina o quão eficiente é cada cooperativa, mas permite identificar quais são as mais ou menos eficientes e a distância entre elas. Esses resultados valem apenas para a amostra analisada, de 
modo que não pode ser generalizado às demais cooperativas de crédito que não foram investigadas nesta pesquisa.

É possível identificar algumas tendências, como uma concentração maior de cooperativas das redes Sicoob e Unicredi entre as mais eficientes e as filiados à rede Sicredi entre as menos eficientes. Devido ao baixo número de cooperativas filiadas a outras redes pertencentes à amostra não é possível identificar tendências no seu comportamento do desempenho, bem como de sua eficiência.

A eficiência das cooperativas é determinada a partir dos seus índices, e as cooperativas filiadas às redes pactuam de determinadas características e políticas de funcionamento comuns para cada rede. Esses fatores podem estar contribuindo para um desempenho econômico-financeiro semelhante entre as cooperativas pertencentes à mesma rede.

A determinação do score de eficiência das cooperativas permite identificar as semelhanças e diferenças entre as cooperativas, observando o score final (Tabela 2). Pelo scorre final, além de observar o ranking de eficiência, pode-se também observar a distância de eficiência entre elas.

A eficiência das cooperativas depende de sua estrutura econômico-financeira, não está relacionada ao seu montante de ativos, ao número de associados, ao montante de receitas entre outros. Pois, de acordo com o ranking do BACEN (2013) a Unicredi João Pessoa é a 25a cooperativa, e, foi a mais eficiente do grupo analisado. A Coopercítrus $1^{\mathrm{a}}$ do ranking do BACEN é a $4^{\mathrm{a}}$ em eficiência. A Sicoob Coocred, $2^{\mathrm{a}}$ colocada no ranking do BACEN é a $18^{\mathrm{a}}$ em eficiência.

As cooperativas de crédito brasileiras podem melhorar sua estrutura, corroborando com Silva (2012), que destacou a possibilidade de crescimento do desempenho das cooperativas, principalmente das atividades de crédito, visando com isso seu desempenho e eficiência, e por conseguinte, o desempenho na principal função que consiste na maximização dos produtos e serviços ofertados aos cooperados e assim, atender suas necessidades de forma eficiente.

Recomenda-se analisar o desempenho de cooperativas de crédito estrangeiras e compará-las com as brasileiras. Partindo do princípio de que as recomendações do WOCCU são utilizadas em diversos países, é possível identificar as interferências do BACEN no desempenho econômico-financeiro das cooperativas de crédito brasileiras.

Em virtude de os resultados aqui apresentados, focarem apenas em aspectos econômicos e financeiros, recomenda-se a inclusão de indicadores sociais e voltados às políticas de funcionamento das cooperativas para determinar a eficiência das cooperativas sob outros aspectos e também para identificar se estes últimos influenciam no desempenho econômico-financeiro das cooperativas de crédito brasileiras.

\section{REFERÊNCIAS}

AGARWAL, P. K.; SINHA, S. K. Financial Performance of Microfi nance Institutions of India. Delhi Business Review, v. 11, n. 2, p. 37-46, 2010.

ALMADA, S. R.; ABREU, M. C. S.; CUNHA, L. T.; SILVA FILHO, J. C. L. Desafios para a Formação de Cooperativas Agrícolas na Cadeia de Suprimento de Biodiesel no Estado do Ceará. REUNA, v. 16, n. 4, p. p. 13-26, 2011.

BACEN - Banco Central Do Brasil. Disponível em: http://www4.bcb.gov.br/top50/port/ArquivoZip.asp. Acesso em 28 de março de 2014.

BRANCH, B.; RICHARDSON, D.; MUKASA, R. World Council of Credit Unions research monograph series. 1998.

BRESSAN, V. G. F.; BRAGA, M. J.; BRESSAN, A. A. Avaliação financeira das cooperativas de crédito rural do estado de Minas Gerais. Organizações Rurais \& Agroindustriais, v. 5, n. 2, 2011.

BRESSAN, V. G. F.; LOPES, A. L. M.; MENEZES, M. R.. Análise de eficiência das cooperativas de crédito brasileiras utilizando informações contábeis. In: $1^{\circ}$ Congresso Integrado de Contabilidade - Governador Valadares/MG, Anais..., 2013.

BRESSAN, V.G.F.; BRAGA, M. J.; BRESSAN, A. A.; RESENDE-FILHO, M. A. Aplicação do Sistema PEARLS 
ao Sicoob-Brasil. Journal of Banking Regulation, v. 9, n. 3, p. 165-186, 2008.

BRESSAN, V.G.F.; BRAGA, M. J.; BRESSAN, A. A.; RESENDE-FILHO, M. A. Uma proposta de indicadores contábeis aplicados às cooperativas de crédito brasileiras. Revista Contabilidade e Controladoria-RC\&C, v. 2, n. 3, 2011a.

BRESSAN, V.G.F.; BRAGA, M. J.; BRESSAN, A. A.; RESENDE-FILHO, M. A. Insolvency evaluation in credit unions: an application of the Pearls system. RAM. Revista de Administração Mackenzie, v. 12, n. 2, p. 113-144, 2011b.

BRESSAN, V.G.F.; BRAGA, M. J.; BRESSAN, A. A.; RESENDE-FILHO, M. A. Uma aplicação do sistema PEARLS às cooperativas de crédito brasileiras-DOI: 10.5700/rausp1011. Revista de Administração, v. 46, n. 3, 2011c.

BULGURCU, B. K. Application of TOPSIS technique for financial performance evaluation of technology firms in Istanbul stock exchange market. Procedia - Social and Behavioral Sciences, v. 62, p. 1033-1040, 2012.

CAMARGOS, M. A.; BARBOSA, F. V. análise do desempenho econômico-financeiro e da criação de sinergias em processos de fusões e aquisições no mercado brasileiro ocorridos entre 1995 e 1999. Caderno de Pesquisas em Administração, São Paulo, v. 12, n. 2, p. 99-115, 2005.

CARVALHO, F.; KALATZIS, F.; DIAZ, M. D. M.; BIALOSKORSKI NETO, S. Mortalidade e Longevidade de Cooperativas de Crédito Brasileiras: uma Aplicação dos Modelos Logit e de Riscos Proporcionais de Cox. In: 9th Congresso USP Controladoria e Contabilidade: Da pesquisa que temos para a pesquisa que precisamos, School of Economics, Business and Accounting, University of Sao Paulo, Sao Paulo. Anais..., 2009.

CHRISTELLE, G. L. Les institutions de microfinance font-elles face à un arbitrage entre les performances financières et le degré de portée sociale? 2009. 74 f. Mémoire (Maitrise en Économique) - Université Du Québec Á Montréal, Montréal, 2009.

CLARK, L. The Credit-Union Legal Framework. II. Journal of Business of the University of Chicago, p. 51-66, 1944.

CROTEAU, J. T. Federal Credit Union Liquidations. The Journal of Business, v. 25, p. 1935-1951, 1952.

DAMBROS, M. A.; LIMA, J. F.; FIGUEIREDO, A. M. Sistema Cooperativo De Crédito Sicredi: Um Estudo Da Eficiência Das Cooperativas Do Paraná. Gestão \& Regionalidade, v. 25, n. 74, 2009.

ERTUGRUL, I.; KARAKASOGLU, N. Performance evaluation of Turkish cement firms with fuzzy analytic hierarchy process and TOPSIS methods. Expert Systems With Applications, v. 36, p. 702-715, 2009.

FERREIRA, C. F. Estrutura, concorrência e performance do setor bancário em um mercado heterogêneo. 2005. 138 f. Tese (Doutorado em Economia) - Faculdade de Economia Administração e Contabilidade, Universidade de São Paulo, SP, 2005.

FERREIRA, M. A. M.; GONÇALVES, R. M. L.; BRAGA, M. J. Investigação do desempenho das cooperativas de crédito de Minas Gerais por meio da Análise Envoltória de Dados (DEA). Economia Aplicada, v. 11, n. 3, p. 425-445, 2007.

FRIED, H. O.; KNOX LOVELL, C. A.; EECKAUT, P. V. Evaluating the performance of US credit unions. Journal of Banking \& Finance, v. 17, n. 2, p. 251-265, 1993.

FRIED; Harold O. LOVELL; C.A.K. Lovell. YAISAWARNG, Suthathip. The impact of mergers on credit union service provision. Journal of Banking \& Finance, vol. 23, p. 367-386, 1999.

FROMAN, L. A. Credit Unions. The Journal of Business of the University of Chicago, v. 8, n. 3, p. 284-296, 1935.

FUKUYAMA, H.; GUERRA, R.; WEBER, W. L. Efficiency and ownership: evidence from Japanese credit cooperatives. Journal of Economics and Business, v. 51, n. 6, p. 473-487, 1999.

GODDARD, J.; MCKILLOP, D.; WILSON, J. O. S. The diversification and financial performance of US credit unions. Journal of Banking \& Finance, v. 32, n. 9, p. 1836-1849, 2008.

JAYAMAHA, A.; MULA, J. M. Financial practices and efficiency of cooperative rural banks in Sri Lanka. In: Proceedings of the 1st International Conference on Business and Information: Researching Realities of Management Phenomenon (ICBI 2010). University of Kelaniya, p. 1-25, 2010. 
KIRKPATRICK, C.; MAIMBO, S. M. The implications of the evolving microfinance agenda for regulatory and supervisory policy. Development Policy Review, v. 20, n. 3, p. 293-304, 2002.

LERMAN, Z.; PARLIAMENT, C. Size and industry effects in the performance of agricultural cooperatives. Agricultural Economics, v. 6, n. 1, p. 15-29, 1991.

MCKEE, D. An economic analysis of credit unions in michigan. The Journal of Finance, v. 21, n. 4, p. 752-752, 1966.

MEURER, S.; MARCON, R. Desempenho de cooperativas: o caso de uma cooperativa de crédito rural. Organizações Rurais \& Agroindustriais, v. 9, n. 3, 2011.

MULINARI, M.; RITTERBUCH, D. de S. Perfil dos colaboradores das cooperativas de crédito frente à essência do cooperativismo. Revista de Administração, v. 9, n. 16, p. p. 59-76, 2013.

RICHARDSON, D. C. Pearls monitoring system. World Council of Credit Unions, Madison, 2002.

RICHARDSON, D. C. Teaching old dogs new tricks: the commercialization of credit unions. World Council of Credit Unions, Aug., 2008.

ROSALEM, V.; SILVA, E. A.; SILVA, F. F.; ALCÂNTARA, V. C. Gestão de cooperativas: um estudo sob o olhar do cooperado. Administração Pública e Gestão Social, v. 1, n. 1, p. 46-66, 2010.

ROSEnBERG, S. A. Credit Unions in North Carolina. The Journal of Business, v. 23, 1950.

ROSSEL-CAMBIER, K. Does Combining Credit with Insurance or Savings Enhance the Organizational Performance of Microfinance Institutions?. Working Paper Centre de Recherche Warocqué-CERMI, 2010/6, Université de Mons, 2010.

SILVA, J. P. Análise financeira das empresas. 5. ed. São Paulo: Atlas, 2001.

SILVA, T. P. Risco positivo na atividade de crédito que otimiza o desempenho econômico-financeiro de cooperativas de crédito. 2012. 225 f. Tese (Doutorado em Ciências Contábeis e Administração) Universidade Regional de Blumenau, Blumenau, 2012.

SMITH, D. J. A theoretic framework for the analysis of credit union decision making. The Journal of Finance, v. 39, n. 4, p. 1155-1168, 1984.

TIAN, Z.; KETSARAPORN, S. Performance benchmarking for building best practice in business competitiveness and case study. International Journal of Networking and Virtual Organisations, v. 12, n. 1, p. 40-55, 2013.

TRINDADE, M. T.; FERREIRA FILHO, F. A.; BIALOSKORSKI NETO, S. Análise do desempenho financeiro das cooperativas de crédito brasileiras nos últimos 10 anos. In: V Encontro de Pesquisadores Latino-Americanos de Cooperativismo, Ribeirão Preto, São Paulo, Anais..., 2008.

VARIAN, H. R. Microeonomic analysis. New York: W.W. Norton, 1992.

WEStON, J. F.; BRIGHAM, E. F. Fundamentos da Administração Financeira. 10. ed. São Paulo: Pearson Education do Brasil, 2000.

WOCCU - World Council of Credit Unions. International Credit Union System. Disponível em: <http://www. woccu.org/memberserv/intlcusystem>. Acesso em 28 de novembro de 2013.

WU, H. Y.; TZENG, G. H.; CHEN, Y. H. A fuzzy MCDM approach for evaluating banking performance based on balanced scorecard. Expert Systems With Applications, v. 36, p. 10135-10147, 2009.

YANG, C. C. The effect of environmental management on environmental performance and firm performance in Taiwanese maritime firms. International Journal of Shipping and Transport Logistics, v. 4, n. 4, p. 393407, 2012.

ZHINGRE, A. P. J. Análisis financiero y aplicación del sistema PEARLS en la cooperativa de ahorro y credito del sindicato de choferes de la ciudad de yanzatza periodo 2010-2011. 2012. 200 f. Tesis (Ingeniaría em Contabilidad e Auditoria) - Universidad Nacional de Loja, Loja, 2012. 